\title{
Spinodal Decomposition in Functionally Graded Super Duplex Stainless Steel and Weld Metal
}

\author{
VAHID A. HOSSEINI, MATTIAS THUVANDER, STEN WESSMAN, \\ and LEIF KARLSSON
}

Low-temperature phase separations $\left(\mathrm{T}<500^{\circ} \mathrm{C}\right)$, resulting in changes in mechanical and corrosion properties, of super duplex stainless steel (SDSS) base and weld metals were investigated for short heat treatment times ( 0.5 to 600 minutes). A novel heat treatment technique, where a stationary arc produces a steady state temperature gradient for selected times, was employed to fabricate functionally graded materials. Three different initial material conditions including 2507 SDSS, remelted 2507 SDSS, and 2509 SDSS weld metal were investigated. Selective etching of ferrite significantly decreased in regions heat treated at $435^{\circ} \mathrm{C}$ to $480{ }^{\circ} \mathrm{C}$ already after 3 minutes due to rapid phase separations. Atom probe tomography results revealed spinodal decomposition of ferrite and precipitation of $\mathrm{Cu}$ particles. Microhardness mapping showed that as-welded microstructure and/or higher Ni content accelerated decomposition. The arc heat treatment technique combined with microhardness mapping and electrolytical etching was found to be a successful approach to evaluate kinetics of low-temperature phase separations in SDSS, particularly at its earlier stages. A time-temperature transformation diagram was proposed showing the kinetics of $475^{\circ} \mathrm{C}$-embrittlement in 2507 SDSS.

https://doi.org/10.1007/s11661-018-4600-9

(C) The Author(s) 2018

\section{INTRODUCTION}

DUPLEX stainless steels deliver an excellent combination of mechanical and corrosion properties, making them an attractive alternative to austenitic and super austenitic stainless steels. ${ }^{[1]}$ However, phase separations occur relatively rapidly below $500^{\circ} \mathrm{C}$, resulting in what is referred to as $475{ }^{\circ} \mathrm{C}$-embrittlement, which restricts their application at temperatures between $250{ }^{\circ} \mathrm{C}$ and $500{ }^{\circ} \mathrm{C}^{[2,3]}$ Spinodal decomposition of $\delta$-ferrite to Fe-rich $(\alpha)$ and Cr-rich $\left(\alpha^{\prime}\right)$ ferrite and the precipitation of $\alpha^{\prime}$ (by nucleation and growth), G-phase, R-phase, $\chi$-phase, nitrides, and $\mathrm{Cu}$-clusters have been reported in this temperature range, which contribute to the embrittlement. $^{[3,4]}$ Super duplex stainless steels (SDSSs) have high contents of $\mathrm{Cr}, \mathrm{Mo}$, and $\mathrm{Ni}$ and are prone to this type of embrittlement which is why kinetics of phase

VAHID A. HOSSEINI is with the Department of Engineering Science, University West, 46186 Trollhättan, Sweden and also with Innovatum AB., Trollhättan, 46129 Trollhättan, Sweden. Contact e-mail: vahid.hosseini@hv.se MATTIAS THUVANDER is with the Department of Physics, Chalmers University of Technology, 41296 Gothenburg, Sweden. STEN WESSMAN and LEIF KARLSSON are with the Department of Engineering Science, University West.

Manuscript submitted November 14, 2017.

Article published online April 17, 2018 transformations play a crucial role in processing and applications of these steels. ${ }^{[5]}$

A considerable variation of data reported in the literature and industrial datasheets points to a knowledge gap about the kinetics of $475^{\circ} \mathrm{C}$-embrittlement in SDSSs. Hilders et al. found that 9 hours heat treatment of 2507 SDSS at $475^{\circ} \mathrm{C}$ did not decrease the impact toughness while it was significantly reduced after 72 hours. ${ }^{[6]}$ Gutiérrez-Vargas et al. observed only minor changes in microhardness after 1-h heat treatment of 2507 SDSS at $475{ }^{\circ} \mathrm{C} \cdot{ }^{[7]}$ An industry datasheet for $2507 \mathrm{SDSS}^{\left[{ }^{[5]}\right.}$ in contrast, introduced a time-temperature transformation (TTT) diagram indicating that only 3 minutes aging at $475^{\circ} \mathrm{C}$ will result in a 50 pct toughness drop in 2507 SDSS.

Several indirect and direct methods can be used to detect $475{ }^{\circ} \mathrm{C}$-embrittlement. Indirect methods monitor the changes in properties caused by the phase separations, which include hardness testing ${ }^{[8]}$ impact toughness testing, ${ }^{[9]}$ magnetic ferrite measurement, ${ }^{10]}$ electrochemical tests, ${ }^{[10]}$ alternating current potential drop, ${ }^{[7]}$ electrical resistance measurement, ${ }^{[1]}$ scanning Kelvin probe force microscopy and magnetic force microscopy, ${ }^{[12]}$ small-angle neutron scattering (SANS) ${ }^{[13]}$ ' etc. Direct methods, on the other hand, detect the phase separations by analyzing the microstructure using scanning and transmission electron microscopy ${ }^{[14]}$ and atom probe tomography (ATP). ${ }^{[15]}$ 
Especially, APT builds a 3D reconstruction of the atomic configuration and provides high spatial resolution allowing to measure nanoscale compositional fluctuations. ${ }^{[6]}$ However, the direct methods are generally more time-consuming, less easily accessible and expensive compared to the indirect methods.

Functionally graded materials (FGMs) have been developed through different processes to tailor the properties for specific purposes. ${ }^{[17]}$ Hosseini et al. ${ }^{[18]}$ recently developed a technique to produce FGM, aiming at facilitating and accelerating microstructural characterization. In this novel technique, a steady-state temperature gradient is produced in a disc by applying a stationary arc on the top side while water cooling on the back side. The arc heat treatment time can be controlled and varied from a few seconds to several hours and the temperature range is from the material liquidus to ambient temperature.

This study aims at investigating the kinetics of $475^{\circ} \mathrm{C}$-embrittlement of SDSS, as existing data are conflicting. The influence of heat treatment times, initial microstructural morphology (hot-rolled and welded), and chemical composition (welding filler wire and base material) have therefore been evaluated. Functionally graded SDSS samples, produced by arc heat treatment, were screened with two indirect methods: electrolytical etching and hardness mapping. The indirect methods were complemented with thermodynamic calculations, $\mathrm{x}$-ray diffraction analysis (XRD), and APT to characterize possible phase separations at short heat treatment times (below 600 minutes). The observed kinetics of $475^{\circ} \mathrm{C}$-embrittlement were summarized in a TTT diagram and compared with available data from literature.

\section{EXPERIMENTAL PROCEDURE}

\section{A. Materials}

Hot-rolled 2507 SDSS plates and type 2509 SDSS welding wire were used to produce base material and weld metal samples for the experiment. The chemical compositions are listed in Table I. Three different materials were investigated:

Base metal (BM) as-received hot-rolled 2507 SDSS 6-mm plate, from Outokumpu Stainless AB, Sweden. Remelted base metal (RBM) weld metal produced by Tungsten Inert Gas (TIG) remelting 2507 SDSS plate material. Remelting with Ar-30 pct $\mathrm{He}-2$ pct $\mathrm{N}_{2}$ allowed to produce a weld microstructure with a similar chemical composition as BM and to investigate the influence of the microstructural morphology on $475^{\circ} \mathrm{C}$-embrittlement. The chemical composition of RBM was not analyzed but is expected to be very similar to the BM except for nitrogen. ${ }^{[19]}$ Hertzman et al. ${ }^{[19]}$ reported that autogenous TIG welding of 2507 SDSS using 2 pct $\mathrm{N}_{2}$ may result in a maximum of $0.03 \mathrm{wt}$ pct drop in the nitrogen content. Therefore, the RBM nitrogen content should not be less than 0.24 wt pct.

Remelted weld metal ( $R W M$ ) A $8 \times 20 \mathrm{~mm}^{2}$ groove was machined in a 2507 SDSS plate and filled with 25 passes of 2509 welding wire, from Elga, Sweden, using TIG welding with Ar-30 pct He- $2 \mathrm{~N}_{2}$. This procedure was used to minimize dilution with $\mathrm{BM}$ in the weld metal. As a final step, the weld was TIG remelted using Ar-30 pet $\mathrm{He}-2$ pet $\mathrm{N}_{2}$ to remove possible secondary phases and homogenize the chemical composition and microstructure. This sample was used to study the influence of chemical composition on the $475{ }^{\circ} \mathrm{C}$-embrittlement. The chemical composition of RWM was measured by LECO combustion technique and optical emission spectrometry, which is listed in Table I.

\section{B. Arc and Furnace Heat Treatment}

A novel arc heat treatment technique was used to create a steady-state temperature gradient in the above-mentioned samples. The process and equipment are schematically shown in Figure 1. A disc-shaped sample (6 mm thick and $\varnothing 99 \mathrm{~mm}$ ) was mounted on a water-cooled chamber and a stationary arc was applied for a selected time. The steady-state temperature gradient formed during the arc heat treatment is shown in Figure 1. An arc current of $100 \mathrm{~A}$ and an arc length of 3 $\mathrm{mm}$ were used to heat treat samples. More details about the arc heat treatment technique are reported by Hosseini et al. in Reference 18.

Arc heat treatment times of $0.5,1,3,10,60$, and 600 minutes were selected to investigate the kinetics of $475^{\circ} \mathrm{C}$-embrittlement in BM. To compare different microstructural morphologies and chemical compositions, 1 and 10 minutes arc heat treatments were applied to RBM and RWM discs. As shown in Figure 1, each specific location in the cross section has a steady-state temperature during the arc heat treatment.

In addition to the arc heat-treated samples, a separate BM sample was heat treated in a furnace with argon atmosphere for 600 minutes at $475^{\circ} \mathrm{C}$ to verify results from the 600 minutes arc heat treatment sample. Microhardness and APT studies were performed on the furnace heat-treated sample.

Table I. Chemical Composition (Weight Percent) of 2507 Type Base Metal, 2509 Welding Wire and Remelted Weld Metal (RWM)

\begin{tabular}{|c|c|c|c|c|c|c|c|c|c|c|c|c|}
\hline & $\mathrm{C}$ & $\mathrm{Si}$ & $\mathrm{Mn}$ & $\mathrm{P}$ & $\mathrm{S}$ & $\mathrm{Cr}$ & $\mathrm{Ni}$ & Mo & $\mathrm{N}$ & $\mathrm{Cu}$ & W & $\mathrm{Fe}$ \\
\hline Base Metal & 0.02 & 0.4 & 0.8 & 0.03 & 0.001 & 25.0 & 6.9 & 3.8 & 0.27 & 0.4 & - & bal. \\
\hline Welding Wire & 0.02 & 0.4 & 0.6 & 0.01 & 0.001 & 25.5 & 9.2 & 4.0 & 0.26 & 0.1 & 0.04 & bal. \\
\hline RWM & 0.01 & 0.4 & 0.6 & 0.02 & 0.001 & 24.8 & 8.9 & 3.8 & 0.22 & 0.1 & 0.03 & bal. \\
\hline
\end{tabular}




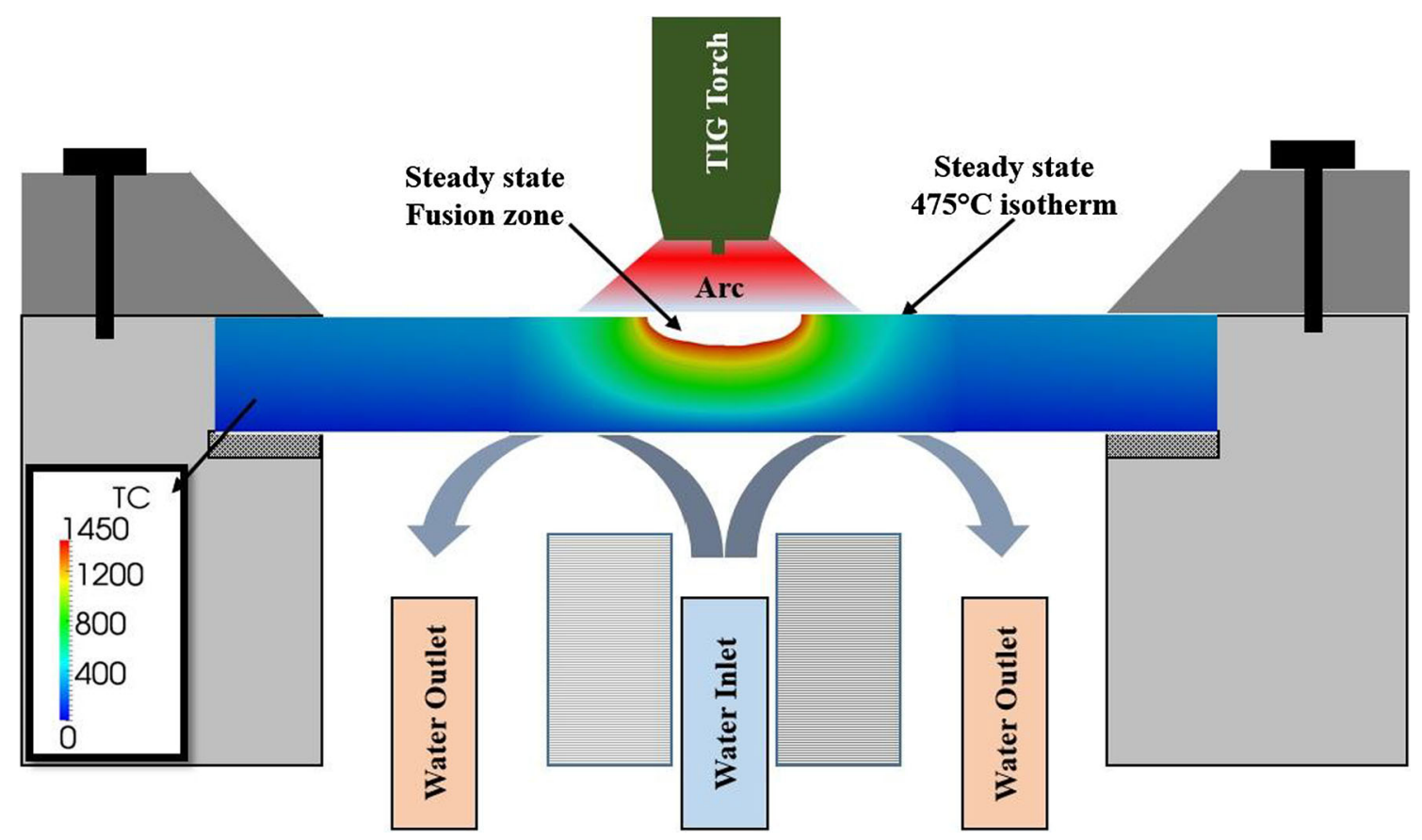

Fig. 1-Schematic illustration of arc heat treatment equipment and temperature distribution in the cross section. The circulating cooling water and the stationary arc made it possible to produce a steady-state temperature gradient.

\section{Characterization}

Optical and scanning electron microscopy, microhardness mapping, XRD, and APT were employed to study phenomena occurring during heat treatment at temperatures below $500{ }^{\circ} \mathrm{C}$.

Cross sections of samples were wet grinded and polished with standard procedures, electrolytically etched using 10 pet $\mathrm{NaOH}$ at $4.0 \mathrm{~V}$ for 4 seconds and studied with an Olympus BX60M optical microscope and a Toshiba TM3000 scanning electron microscope (SEM). Ferrite numbers of materials before arc heat treatment were measured by a Fisher Feritscope.

Microhardness mapping was carried out with a Struers DuraScan 80 automated hardness tester on polished samples following the ASTM E384-10 standard. An indenter load of $200 \mathrm{~g}$ with a dwell time of 15 seconds was used. The microhardness of ferrite and austenite in the furnace heat-treated sample was measured with an indenter load of $10 \mathrm{~g}$.

To investigate the possible formation of new phases, XRD analysis was employed on the as-received BM and after 600 minutes arc heat treatment at locations heat treated between $400{ }^{\circ} \mathrm{C}$ and $550{ }^{\circ} \mathrm{C}$. A Bruker D8 Discover with a Co-K $\mathrm{K}_{\alpha} \mathrm{X}$-ray source $\left(k=1.78901 \AA^{-1}\right)$ was utilized with the following parameters: $40 \mathrm{~mA}, 35$ $\mathrm{kV}, 2 \theta=45$ tp $114^{\circ}$, a $2 \theta$-scan step size of $0.02^{\circ}$, an exposure time of 2.6 seconds for each step and a spot diameter of $200 \mu \mathrm{m}$.

The furnace heat-treated sample was analyzed by the APT technique. Rods with the dimension of $0.3 \times 0.3 \times 15 \mathrm{~mm}^{3}$ were produced by low speed cutting. Then, each rod was electro-polished to produce two needle-shaped specimens suitable for APT by a standard two-stage electro-polishing method. ${ }^{[14]}$ A local electrode atom probe, LEAP $3000 \mathrm{X} \mathrm{HR}^{\mathrm{TM}}$, equipped with a reflectron for improved mass resolution was employed. Analysis was done at $55 \mathrm{~K}$ with a 20 pct voltage pulse fraction, a pulse frequency of $200 \mathrm{kHz}$ and an evaporation rate of 1 pct. The software IVAS 3.4 .3 was used to analyze the three-dimensional (3D) data. A line profile was extracted from a cylinder with a diameter of $2 \mathrm{~nm}$ and a step-size of $1 \mathrm{~nm}$. Wavelength and amplitude of spinodal decomposition were determined using the radial distribution function (RDF) approach, which represents the average radial concentration profile starting from each and every detected atom of the chosen elements. The (bulk normalized) RDF can be expressed as

$$
\operatorname{RDF}_{E}(r)=C_{E}(r) / C_{0}=\left(N_{\mathrm{A}}(r) / N(r)\right) / C_{0},
$$

where $C_{\mathrm{E}}$ is the atomic composition of element $E$ at a distance $r ; \mathrm{C}_{0}$ is the average composition of element $E$ in the analyzed volume; $N_{E}(r)$ is the total number of atom $E$ at distance $r$, and $N(r)$ is the total number of atoms of all elements at distance $r$. The $\mathrm{Cr}$ amplitude was estimated from the $\mathrm{RDF}_{\mathrm{Cr}}$ at zero and the theoretical $\mathrm{RDF}_{\mathrm{Cr}}$ assumed by a one-dimensional sinusoidal concentration profile $\left(A=C_{0} \sqrt{2(R D F C r 0)-1)}\right)$. The chemical composition of $\alpha$ and $\alpha^{\prime}$ was measured within volumes defined by iso-concentration surfaces with thresholds of 70 at. pct $\mathrm{Fe}$ and 30 at. pet $\mathrm{Cr}$, respectively. The standard deviations were obtained from the chemical compositions of nine sub-volumes for each phase (austenite, ferrite, $\alpha$, and $\alpha^{\prime}$ ). More details about the RDF have been reported by Zhou et al. ${ }^{[15,20]}$ 


\section{Modeling and Thermodynamic Calculations}

Temperature distributions and weld pool geometries were stable and equal for different arc heat treatment times, as was verified by thermocouples attached to the samples showing constant temperatures during the arc heat treatments. To model the temperature distribution in the cross section of the arc heat-treated samples, a 2D conductive heat transfer was considered and the model was calibrated with data recorded by thermocouples attached on the top and back sides of the sample. The steady-state temperature field was modeled using the open source computational software OpenFOAM ${ }^{\circledR}$ as reported in the References 18 and 21. Thermal and physical properties of 2507 and 2509 alloys, calculated by JMatPro, are very similar and the same model for the temperature distribution was therefore used for BM, RBM, and RWM.

Equilibrium phase fractions between $400{ }^{\circ} \mathrm{C}$ and $500{ }^{\circ} \mathrm{C}$ and kinetic of $\alpha^{\prime}$ formation were calculated using JMatPro, Version 6.2.1, for the actual chemical compositions of the BM, RBM (with 0.235 wt pet N), and RWM (Table I). The equilibrium phase fractions and chemical composition of different phases for the total ferrite chemical composition measured by APT were also calculated between $400{ }^{\circ} \mathrm{C}$ and $600{ }^{\circ} \mathrm{C}$.

\section{RESULTS}

\section{A. Thermodynamic Calculations}

Equilibrium phase fraction diagrams for 2507 SDSS $\mathrm{BM}$ and RWM compositions for the temperature range of $400{ }^{\circ} \mathrm{C}$ to $500{ }^{\circ} \mathrm{C}$ are presented in Figure 2. The results of the calculations can be summarized as follows:

- $\quad \alpha^{\prime}$ forms below about $480{ }^{\circ} \mathrm{C}$ and $470{ }^{\circ} \mathrm{C}$ for $\mathrm{BM}$ and RWM compositions, respectively.

- The fractions of $\alpha$ and $\alpha^{\prime}$ increase with decreasing temperature. The fraction of $\alpha$ is lower for the welding wire, while the fractions of $\alpha^{\prime}$ are very similar for the two compositions.

- Austenite fractions are higher for the RWM. The austenite fractions decrease slightly with decreasing temperature for both compositions.

- As shown in Figure 2, Laves, Pi-nitride, and carbide fractions are constant in this temperature range for both compositions, but $\mathrm{G}$ phase fraction increases with decreasing temperature and its fractions are lower for RWM.

- $\mathrm{Cu}$ is present in the $\mathrm{BM}$, but not in RWM.

An equilibrium phase fraction diagram was also calculated for RBM, with a nitrogen content of 0.235 wt pct. It was found that different RBM and BM nitrogen contents did not have any significant influence on the phase balance in the temperature range considered.

\section{B. Microstructure and Hardness Before Heat Treatment}

The three different initial microstructures and corresponding hardness maps are shown in Figure 3. The BM has an as-rolled microstructure with elongated austenite and ferrite grains. The remelted base metal has a ferritic matrix with grain boundary, Widmanstätten, and intragranular austenite. The remelted weld metal has a lower ferrite fraction compared to RBM, but a similar microstructural morphology. The ferrite numbers of $\mathrm{BM}, \mathrm{RBM}$, and RWM, measured by Feritscope, were $53 \pm 4,63 \pm 4$, and $50 \pm 2 \mathrm{FN}$, respectively. As may be seen in Figures 3(d), (e), and (f), the highest overall hardness before arc heat treatment was found for RBM and the lowest for RWM.

\section{Temperature Distribution and Etching Behavior}

The temperature distribution and corresponding microstructure for a sample arc heat-treated 60 minutes are displayed in Figure 4. It can be seen that the etching response depends on the heat treatment temperature and in particular there is a distinguishable light etching band corresponding to a temperature of about $475^{\circ} \mathrm{C}$.

Only ferrite and austenite were found by OM, SEM, and XRD in regions heat treated below approximately $560{ }^{\circ} \mathrm{C}$. The microstructure of as-received and 600 minutes arc heat-treated $\mathrm{BM}$ (on the $475^{\circ} \mathrm{C}$ isotherm), etched electrolytically with 10 pet $\mathrm{NaOH}$, is shown in Figure 5. Interestingly, less selective etching of the ferrite was observed after the 600 minutes arc heat treatment, resulting in a lower contrast between ferrite and austenite. Furthermore, the maximum hardness in the as-received and arc heat-treated BM were $295 \mathrm{HV} 0.2$ and $340 \mathrm{HV} 0.2$, respectively. These observations indicate that phase separations occurred during the arc heat treatment, but on a scale too fine to be identified with optical and scanning electron microscopes. More details about the characteristics of the phase separations were explored by APT and are presented in Section III-G.

\section{Functionally Graded Base Metal}

Cross sections of the arc heat-treated BM samples for different heat treatment times are shown in Figure 6. A bright band appeared after etching in the 3 minutes arc heat-treated sample which became more visible and wider for longer heat treatment times, which likely is related to phase transformation taking place.

Microhardness maps of arc heat-treated BM samples are shown in Figure 7. The first indications of a high hardness band around the $475{ }^{\circ} \mathrm{C}$ isotherm were found in some regions of the 3 minutes arc heat-treated sample. These high hardness regions were found at mid thickness where the bright band is slightly wider in Figure 6. A band with the highest hardness was seen after 600 minutes.

\section{E. Functionally Graded Remelted Base and Weld Metal}

Cross sections and hardness maps of RBM and RWM arc heat treated for 1 minute or 10 minutes are shown in Figure 8. No bright bands were found in the etched cross sections of RBM and RWM after the 1 minute heat treatment but they appeared after 10 minutes (see red arrows). The microhardness maps show high 

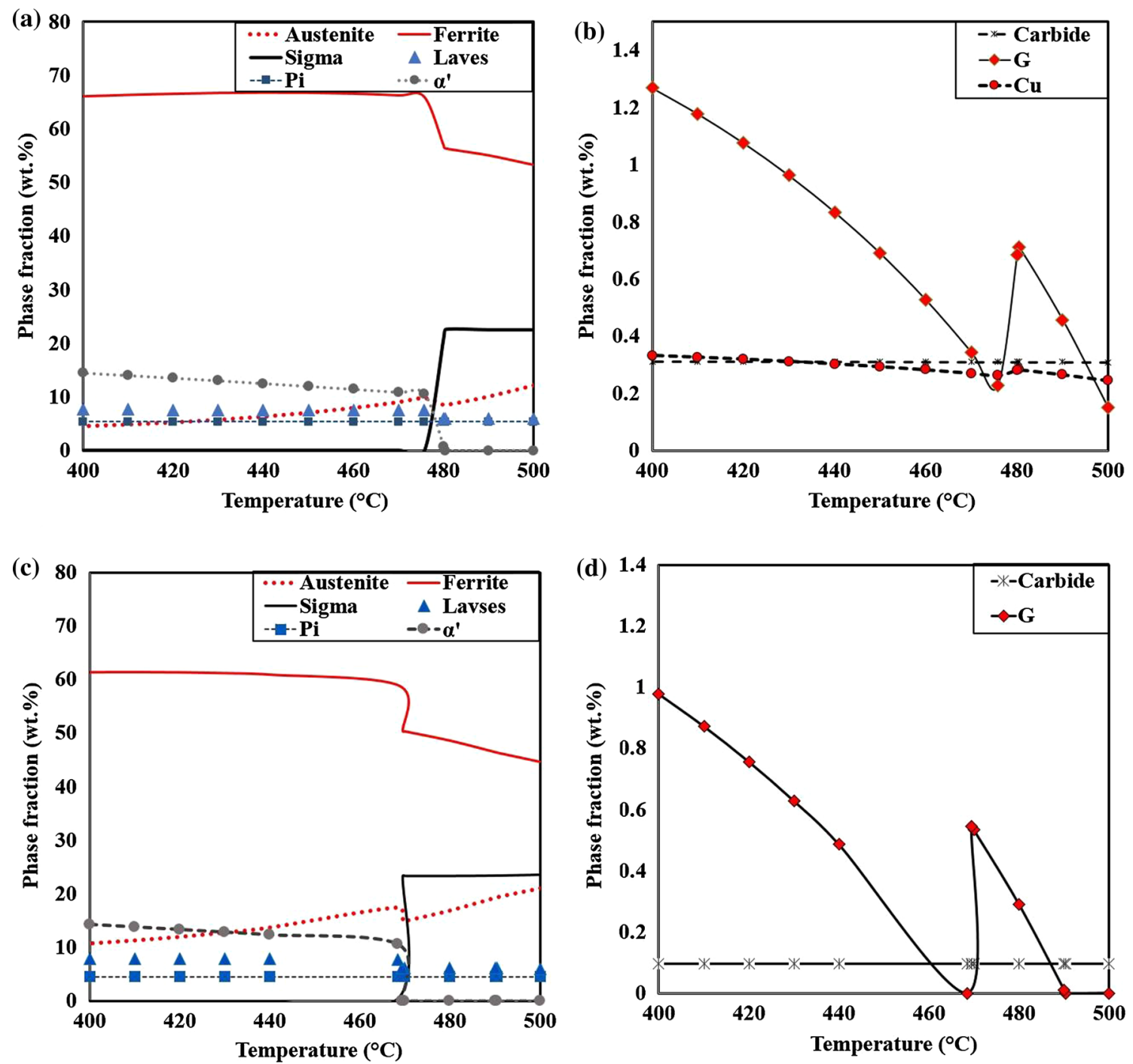

Fig. 2-Equilibrium phase fraction diagrams for compositions corresponding to 2507 SDSS BM and RWM between $400{ }^{\circ} \mathrm{C}$ and $500{ }^{\circ} \mathrm{C}$. (a) Major phases in 2507 SDSS BM, showing $\alpha^{\prime}$ forming at temperatures below $480{ }^{\circ} \mathrm{C}$. (b) Minor phases 2507 SDSS BM. (c) Major phases for RWM, showing $\alpha^{\prime}$ forming at temperatures below $470{ }^{\circ} \mathrm{C}$. (d) Minor phases for RWM.

hardness in the corresponding position after 10 minutes arc heat treatment but not after 1 minute.

\section{F. Phase Separation Temperatures and Hardness Ranges}

In the present section, the observations made in the microhardness maps and cross sections are quantified in terms of heat treatment temperatures and hardness ranges. The temperature range was determined by correlating locations of light etching bands to temperature distribution maps. The hardness and temperature ranges are listed in Table II.

The temperature range, estimated from the width of the light etching bands, increased from $45^{\circ} \mathrm{C}$ after 3 minutes to $95{ }^{\circ} \mathrm{C}$ after 600 minutes in the $\mathrm{BM}$. This was a result of an increase of the maximum temperature for the phase separations of $20{ }^{\circ} \mathrm{C}$ and a decrease of the minimum temperature of $30^{\circ} \mathrm{C}$. Maximum hardness increased about $45 \mathrm{HV}$ after 600 minutes arc heat treatment in the BM.

The temperature ranges were quite similar in BM, $\mathrm{RBM}$, and RWM after 10 minutes arc heat treatment. However, the hardness was higher for RBM than for the $\mathrm{BM}$ and RWM after 10 minutes heat treatment.

As can be seen in the hardness maps and cross sections, different etching responses and higher hardness values are present in the arc heat-treated samples at temperatures above $550{ }^{\circ} \mathrm{C}$, which is due to the precipitation of secondary phases such as $\sigma$ and $\chi$. However, the investigation of the above-mentioned observations is not the focus of this study and will be the subject of other publications. 

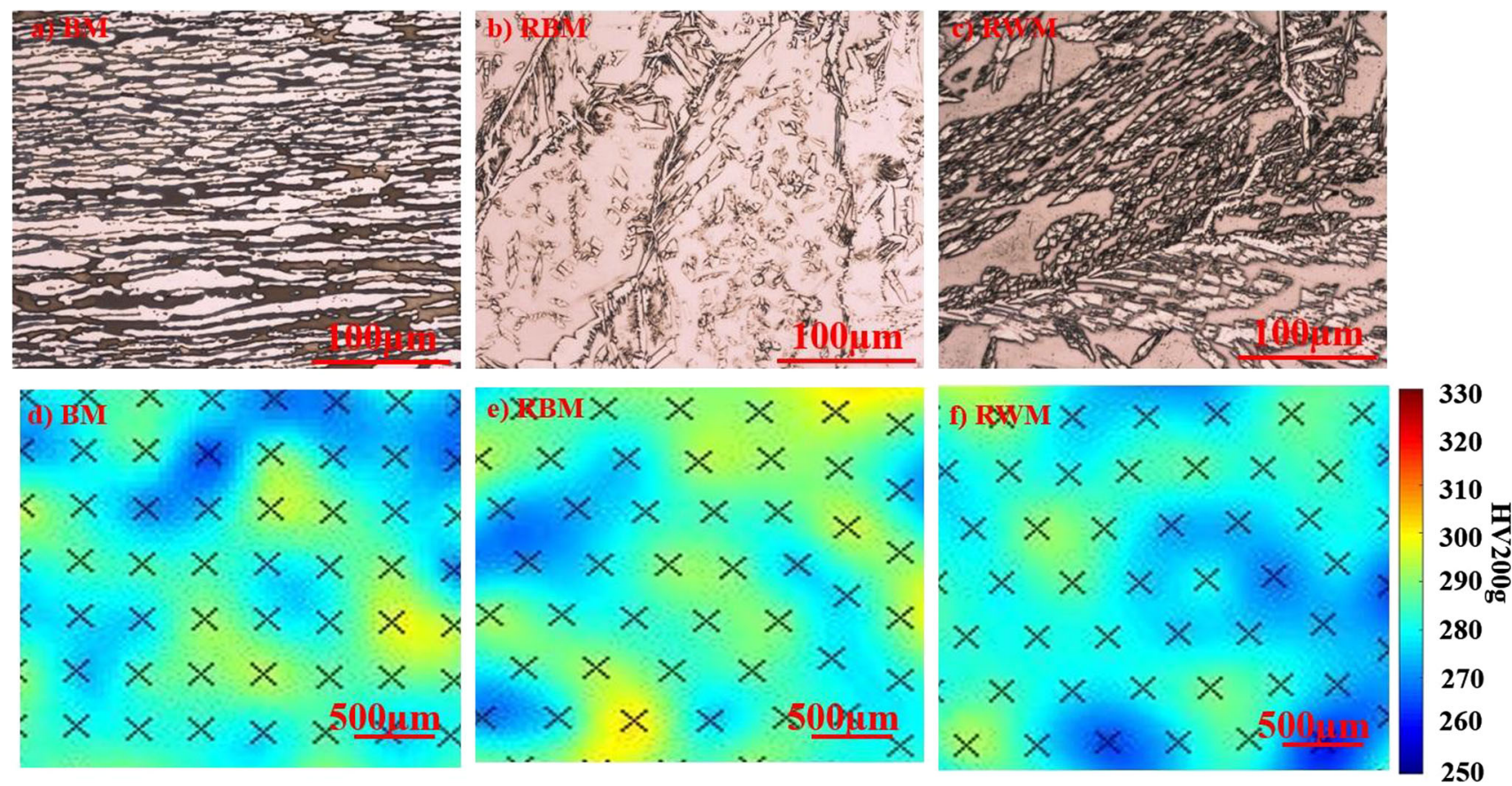

Fig. 3-Optical micrographs and hardness maps of steel and weld metals before heat treatment. ( $a$, $d)$ Base metal (BM), $(b, e)$ remelted base metal (RBM), $(c, f)$ remelted weld metal (RWM). Overall hardness is highest in RBM and lowest in RWM.

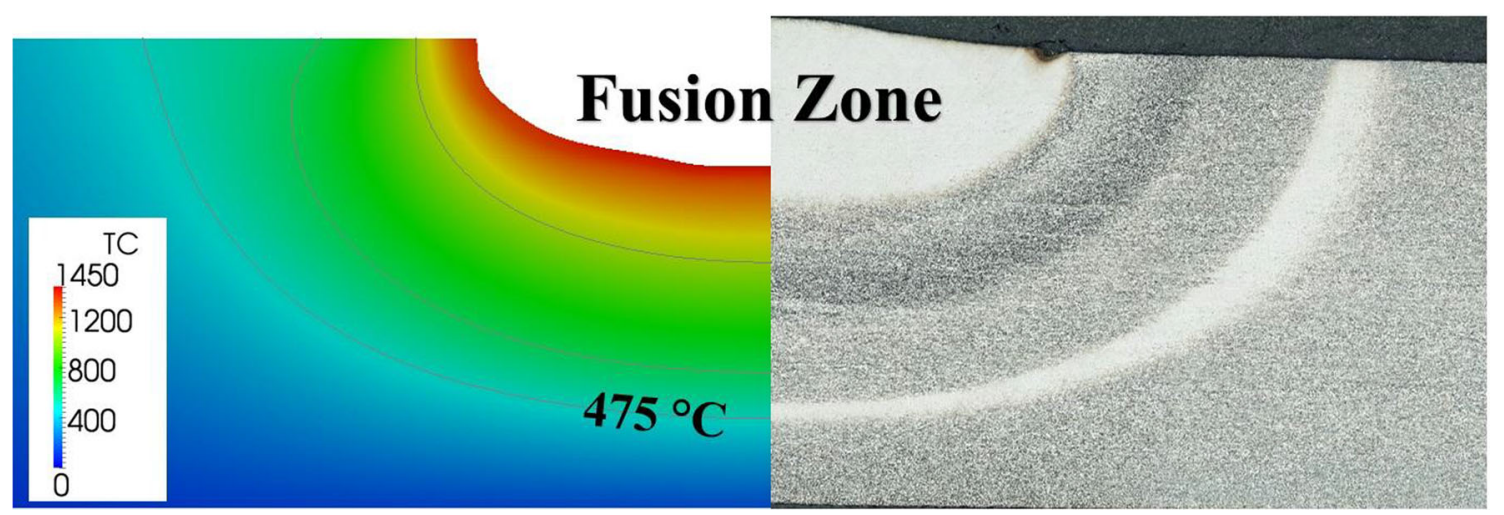

Fig. 4-Temperature distribution (left) and cross section of sample arc heat treated (right) for 60 min. Note the light etching band (spinodal band) at temperatures about $475^{\circ} \mathrm{C}$.

\section{G. Phase Separation Studies}

As explained in the experimental section, a separate sample was heat treated in a furnace at $475^{\circ} \mathrm{C}$ for 600 minutes to verify the arc heat treatment results. The hardness of the ferrite before and after the heat treatment were 247 to $252 \mathrm{HV} 0.01$ and 360 to 390 HV0.01, respectively, while the hardness of the austenite remained fairly constant at 250 to $280 \mathrm{HV} 0.01$. In order to characterize the phase separations occurring in the ferrite, APT was performed on two samples prepared to contain only ferrite and only austenite, respectively.

Iso-concentration surfaces for high $\mathrm{Cr}$ (more than 30 at. pct) and high Fe (more than 70 at. pct) regions in ferrite are illustrated by blue and red, respectively, in Figure 9(a). The APT results clearly show the separation of $\mathrm{Cr}$ and $\mathrm{Fe}$ with, as shown in Figure 9(b), the concentration of $\mathrm{Cr}$ gradually increasing towards the center of each region as is characteristic of spinodal decomposition.

Line profiles from a cylinder with a $2-\mathrm{nm}$ diameter is shown in Figure 10(a), illustrating phase separation into $\mathrm{Fe}-$ rich and $\mathrm{Cr}$-rich ferrite. Normalized $\mathrm{Cr}-\mathrm{Cr}$ and Cr-Fe RDF curves are shown in Figure 10(b). As can be seen, $\mathrm{Cr}-\mathrm{Cr}$ shows a strong positive interaction, whereas $\mathrm{Cr}-\mathrm{Fe}$ has a negative interaction. The spinodal wavelength and amplitude of $\mathrm{Cr}$-rich regions, calculated by the RDF method, are $10 \pm 1 \mathrm{~nm}$ and $14 \pm 1$ at. pct, respectively.

The compositions of austenite, total ferrite, $\alpha^{\prime}$, and $\alpha$ are listed in Table III. The $\alpha^{\prime}$ had a $\mathrm{Cr}$ concentration of 41.3 at. pct, which dropped to 13.7 at. pet in $\alpha$. In addition, $\alpha^{\prime}$ and $\alpha$ have different distributions of other 

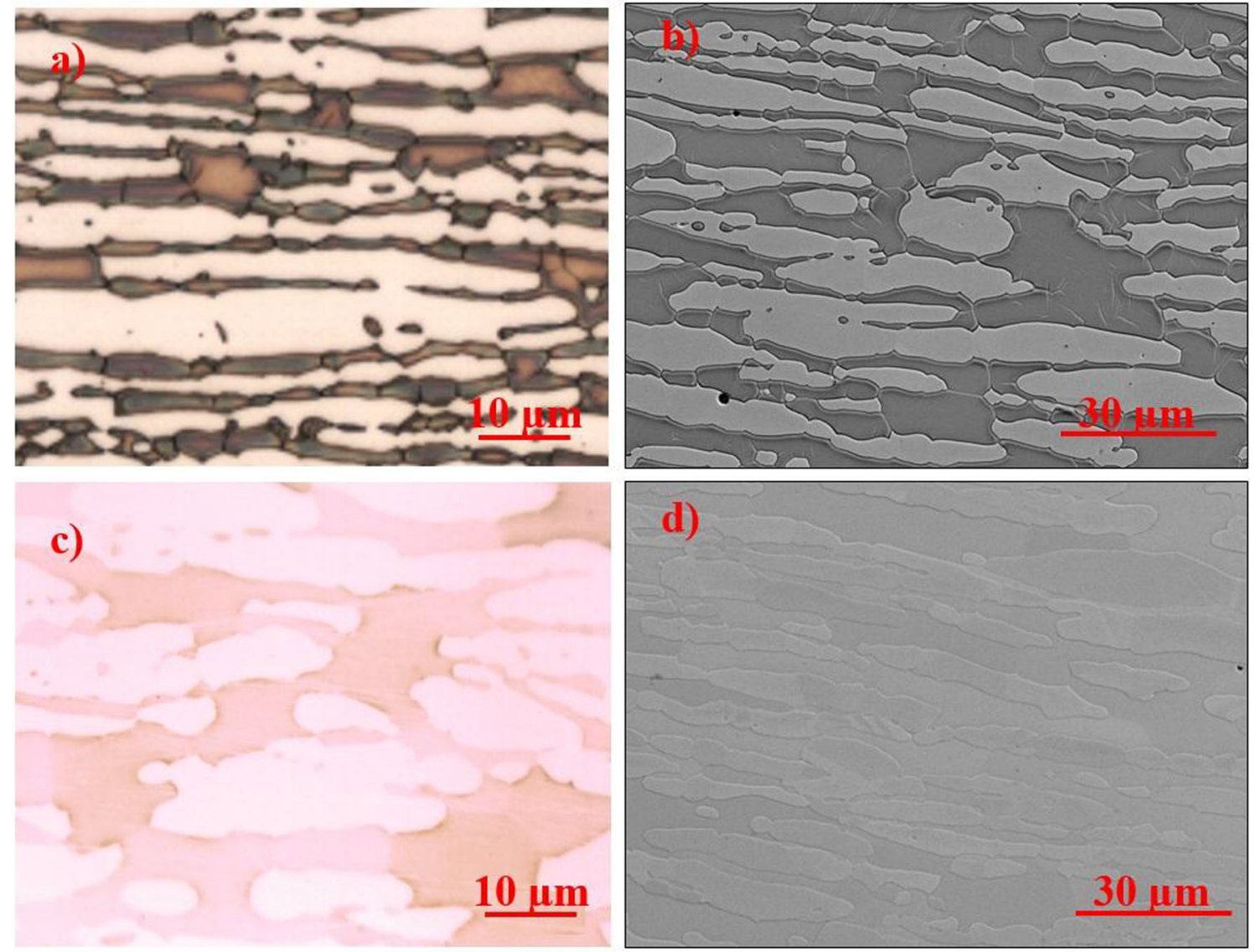

Fig. 5- (a) Optical and (b) SEM micrographs of the specimen before arc heat treatment. $(c)$ Optical and $(d)$ SEM micrographs from the $475{ }^{\circ} \mathrm{C}$ isotherm region of the specimen after $600 \mathrm{~min}$ arc heat treatment. Specimens were etched electrolytically with $10 \mathrm{pct} \mathrm{NaOH}$. The selective etching of ferrite significantly decreased after $600 \mathrm{~min}$ arc heat treatment.

alloying elements, where $\alpha^{\prime}$ is enriched in Mo and Si and depleted in $\mathrm{Ni}$, as also observed in a weld metal by Zhou et al. ${ }^{[15]}$

Almost pure $\mathrm{Cu}$ precipitates containing some $\mathrm{Ni}$ were also found in the ferrite (Figure 9(c)). The Cu-particle number density was about $1.6 \times 10^{22} \mathrm{~m}^{-3}$ and they had an average diameter of $4.2 \pm 0.4 \mathrm{~nm}$. No traces of the other phases suggested by thermodynamic calculations were observed.

\section{DISCUSSION}

In the present section, the characteristics of phase separations, the methods of monitoring, and kinetics are discussed. Finally, a TTT diagram for 2507 type SDSS at temperatures below $500{ }^{\circ} \mathrm{C}$ is proposed.

\section{A. Characteristics of Phase Separations}

The thermodynamic calculations predicted the stability of $\alpha+\alpha^{\prime}, \mathrm{Cu}$ precipitates and austenite at $475^{\circ} \mathrm{C}$, which were detected by a combination of APT and XRD. The comparison of the experimental data with the calculated $\alpha^{\prime}$ fractions is, however, not meaningful for spinodal decomposition as there is a gradual change of $\mathrm{Fe}$ and $\mathrm{Cr}$ concentrations. Therefore, the amplitude and wavelength may be a better indicator of the degree of spinodal decomposition. In addition, the equilibrium phase fractions will not be achieved after 600 minutes. Consequently, the absence of other phases, predicted by thermodynamic calculations, was not unexpected.

A minor degree of $\mathrm{Cr}$ and $\mathrm{Fe}$ separation has been reported even in as quenched 2507 SDSS. ${ }^{[2,23]}$ However, the $\mathrm{Cr}$ amplitude of 14 at. pct and wavelength of $10.5 \mathrm{~nm}$ for the spinodal decomposition measured in this study indicate that the spinodal decomposition was notably developed after 600 minutes heat treatment at $475^{\circ} \mathrm{C}$ compared to the initial state of the microstructure.

The increase in the hardness of ferrite confirms that phase separations causing $475^{\circ} \mathrm{C}$-embrittlement occurred during the 600-minute heat treatment of the BM. The absence of other known brittle phases such $\mathrm{G}$, $\chi, \mathrm{R}$, carbides, and nitrides, observed in other studies, ${ }^{[3,4,24,25]}$ suggests that spinodal decomposition is the main cause of earlier stage $475^{\circ} \mathrm{C}$-embrittlement. This is supported by Pettersson et al. ${ }^{[22]}$ who found that also a spinodal wavelength of $4 \mathrm{~nm}$ and $\mathrm{Cr}$ amplitude of 8.6 at. pct, corresponding to much earlier stages compared to the 600 minutes heat treatment, resulted in 40 pct toughness drop after 6000 hours aging at $300{ }^{\circ} \mathrm{C}$. The 

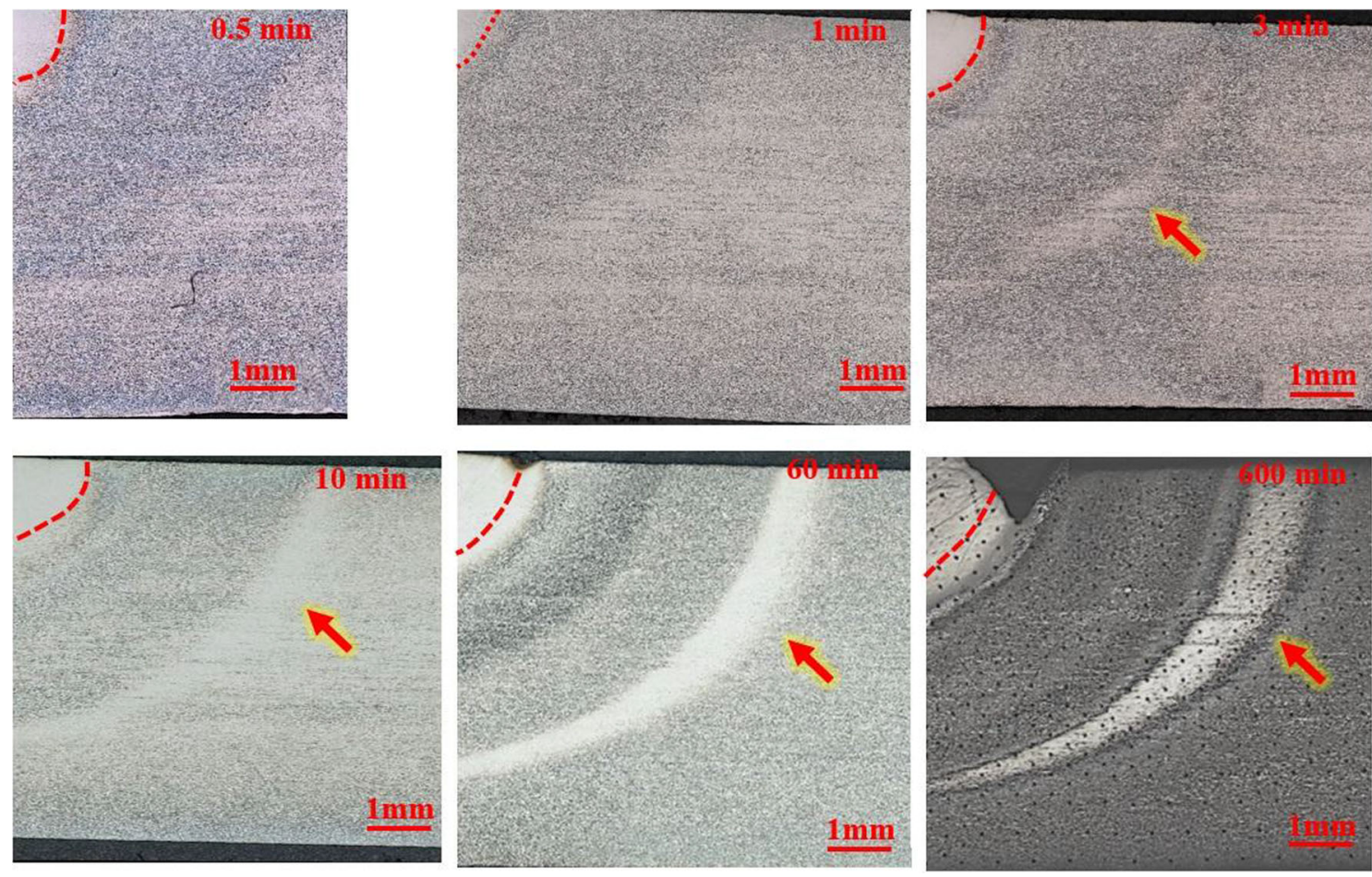

Fig. 6-Electrolytically etched cross sections of BM samples arc heat treated from 0.5 to $600 \mathrm{~min}$. The red broken lines show the position of the fusion boundary. A light etching band around the $475{ }^{\circ} \mathrm{C}$ isotherm formed after 3-min heat treatment (red arrow) and become wider and more visible at longer heat treatment times (Color figure online).
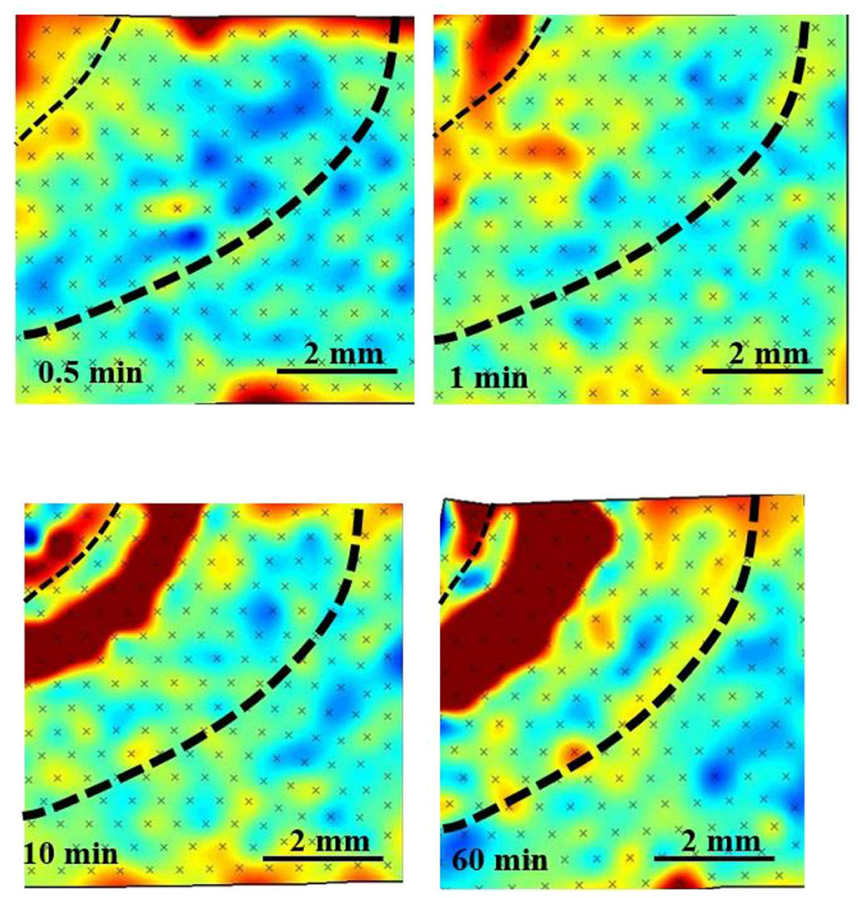
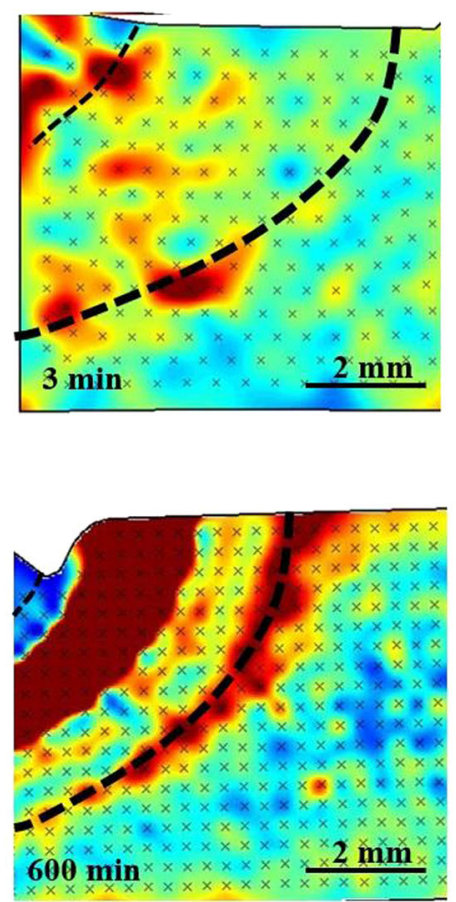

330

320

310

300

స్ํำ

280

270

260

250

Fig. 7-Microhardness map of BM samples arc heat treated from 0.5 to $600 \mathrm{~min}$. In each map, the left broken line shows the position of the fusion boundary and the right broken line the $475{ }^{\circ} \mathrm{C}$ isotherm. The first indications of a high hardness band at $475{ }^{\circ} \mathrm{C}$ were seen after 3 min and the highest hardness after $600 \mathrm{~min}$.

few small $\mathrm{Cu}$ particles, however, would not be expected to cause significant hardening compared to the spinodal decomposition.
In addition to the equilibrium phase fractions presented in Section III-A, thermodynamic calculations were also performed for the chemical composition of the 

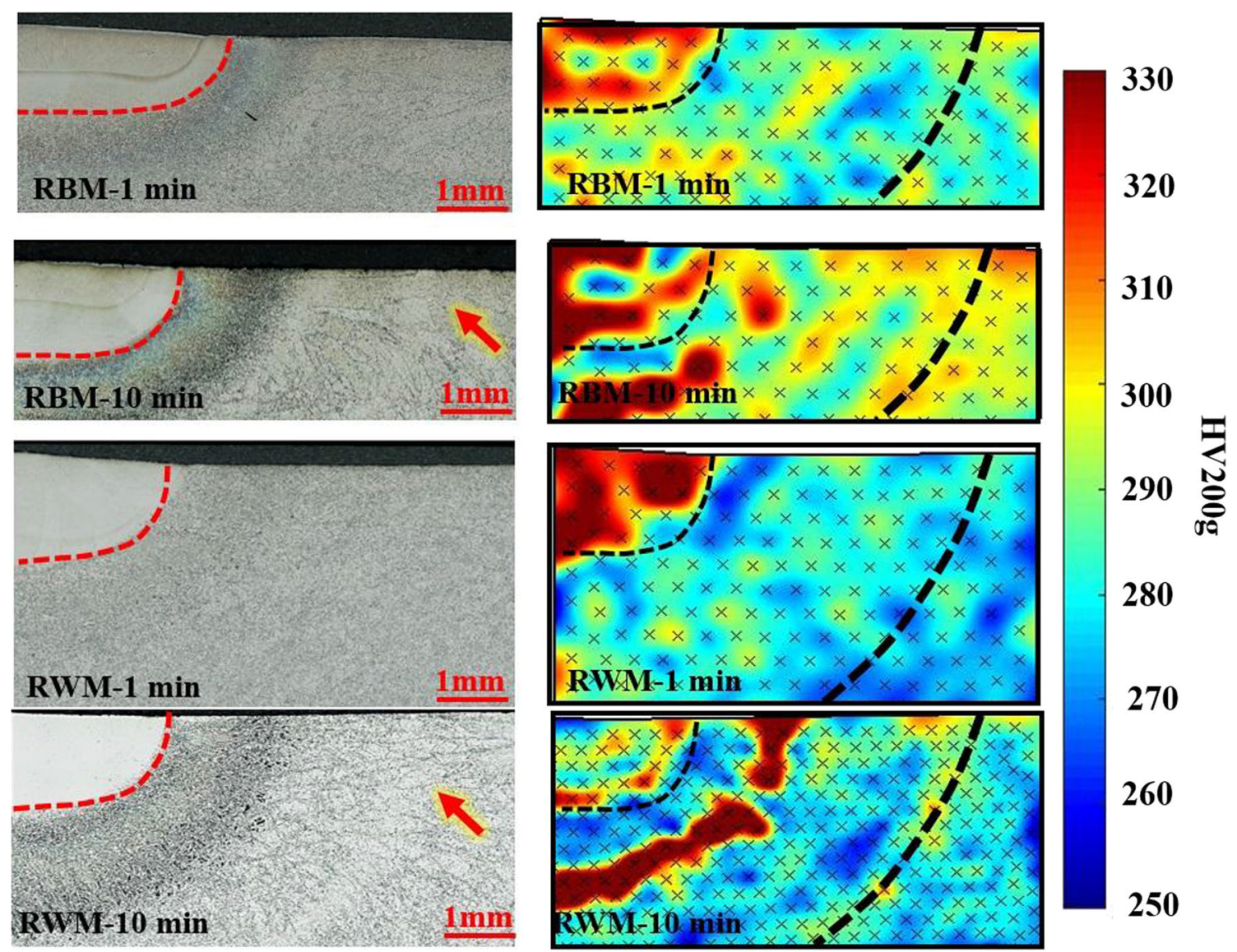

280

270

260

250

Fig. 8 - Cross sections and microhardness maps of remelted base metal (RBM) and remelted weld metal (RWM) after 1 and 10 min arc heat treatment. The red broken lines indicate the position of the fusion boundary and arrows show the position of the light etching band. In the hardness maps, the left broken line shows the position of the fusion boundary and the right broken line shows the $475^{\circ} \mathrm{C}$ isotherm (Color figure online).

Table II. Hardness and Temperature Ranges of Light Etching High Hardness Band for Arc Heat-Treated Samples

\begin{tabular}{|c|c|c|c|}
\hline Time & Sample & $\begin{array}{c}\text { Hardness Range in } \\
\text { High Hardness } \\
\text { Band }\end{array}$ & $\begin{array}{l}\text { T-Range } \\
\text { by Etching }\end{array}$ \\
\hline \multirow{4}{*}{$\begin{array}{l}\text { Before arc } \\
\text { heat treatment }\end{array}$} & $\mathrm{BM}$ & $275-295$ & - \\
\hline & $\mathrm{RBM}$ & $275-300$ & - \\
\hline & RMW & $260-285$ & - \\
\hline & $\mathrm{BM}$ & no change & - \\
\hline \multirow[t]{3}{*}{$1 \mathrm{~min}$} & $\mathrm{BM}$ & no change & - \\
\hline & $\mathrm{RBM}$ & no change & - \\
\hline & RWM & no change & - \\
\hline $3 \mathrm{~min}$ & $\mathrm{BM}$ & no change* & $435-480$ \\
\hline \multirow{3}{*}{$10 \mathrm{~min}$} & $\mathrm{BM}$ & 300 & $435-490$ \\
\hline & RBM & $300-315$ & $440-490$ \\
\hline & RWM & $290-310$ & $440-490$ \\
\hline $60 \mathrm{~min}$ & $\mathrm{BM}$ & $300-310$ & $415-495$ \\
\hline $600 \min$ & $\mathrm{BM}$ & $300-340$ & $405-500$ \\
\hline
\end{tabular}

*Some locations showed high hardness but did not form a clearly distinguishable band.

total ferrite detailed in Table III, only considering $\alpha, \alpha^{\prime}$, and $\mathrm{Cu}$ phase. The absence of other phases in the calculations results in an increase in the predicted spinodal decomposition temperature to $600{ }^{\circ} \mathrm{C}$, which supports the higher measured decomposition temperature $\left(500{ }^{\circ} \mathrm{C}\right.$ after 600 minutes arc heat treatment) compared to the previously calculated equilibrium temperature $\left(480{ }^{\circ} \mathrm{C}\right)$ in Section III-A. These calculations also show that $\alpha^{\prime}$ is enriched in $\mathrm{Cr}$, Mo, and Mn, but depleted in $\mathrm{Fe}$ and $\mathrm{Ni}$ compared to the total ferrite chemical composition, which is in good agreement with compositions presented in Table III. The measured and calculated contents for each element are, as expected, different due to the much longer time needed to approach the equilibrium condition.

\section{B. Monitoring Phase Separations}

In addition to APT, electrolytical etching after 3 minutes or longer and microhardness mapping after 10 minutes or longer arc heat treatment revealed changes that confirm phase separations have occurred in the FGMs. However, SEM and XRD failed to detect these even after 600-minute arc heat treatment.

The FGMs produced in this study provided an opportunity to compare the etching response of regions heat treated at different temperatures in one single sample for each heat treatment time and made it possible to characterize the phase separations based on changes in the etching behavior of ferrite as the austenite 
Table III. Compositions Measured by APT of Austenite, Ferrite (Total Ferrite), and of $\alpha^{\prime}$ and $\alpha$

\begin{tabular}{|c|c|c|c|c|c|c|c|c|}
\hline \multirow[b]{2}{*}{ Elements } & \multicolumn{2}{|c|}{ Austenite } & \multicolumn{2}{|c|}{ Total Ferrite } & \multicolumn{2}{|c|}{$\alpha^{\prime}$} & \multicolumn{2}{|c|}{$\alpha$} \\
\hline & $\begin{array}{l}\text { Conc. } \\
\text { (At. Pct) }\end{array}$ & $\begin{array}{c}\text { Error } \\
\text { (At. Pct) }\end{array}$ & $\begin{array}{l}\text { Conc. } \\
\text { (At. Pct) }\end{array}$ & $\begin{array}{c}\text { Error } \\
\text { (At. Pct) }\end{array}$ & $\begin{array}{l}\text { Conc. } \\
\text { (At. Pct) }\end{array}$ & $\begin{array}{c}\text { Error } \\
\text { (At. Pct) }\end{array}$ & $\begin{array}{l}\text { Conc. } \\
\text { (At. Pct) }\end{array}$ & $\begin{array}{c}\text { Error } \\
\text { (At. Pct) }\end{array}$ \\
\hline $\mathrm{Cr}$ & 25.7 & 0.3 & 26.7 & 0.8 & 41.3 & 0.5 & 13.7 & 0.4 \\
\hline $\mathrm{Fe}$ & 59.6 & 1.0 & 62.6 & 0.8 & 48.5 & 0.5 & 76.3 & 0.3 \\
\hline $\mathrm{Ni}$ & 7.9 & 0.2 & 5.4 & 0.1 & 4.4 & 0.1 & 5.8 & 0.1 \\
\hline $\mathrm{C}$ & 0.37 & 0.13 & $<0.009$ & - & $<0.006$ & - & $<0.009$ & - \\
\hline $\mathrm{N}$ & 1.49 & 0.12 & $<0.008$ & - & $<0.013$ & - & $<0.016$ & - \\
\hline Mo & 1.9 & 0.1 & 2.9 & 0.1 & 3.4 & 0.2 & 2.1 & 0.1 \\
\hline $\mathrm{Si}$ & 1.21 & 0.05 & 1.05 & 0.03 & 1.14 & 0.04 & 0.85 & 0.05 \\
\hline $\mathrm{P}$ & 0.03 & 0.01 & 0.12 & 0.05 & 0.13 & 0.05 & 0.11 & 0.04 \\
\hline $\mathrm{Mn}$ & 0.72 & 0.04 & 0.60 & 0.06 & 0.66 & 0.06 & 0.46 & 0.07 \\
\hline $\mathrm{Cu}$ & 0.32 & 0.06 & 0.24 & 0.04 & 0.13 & 0.01 & 0.23 & 0.02 \\
\hline
\end{tabular}

was largely unaffected. The electrolytical etching response is the result of changes in the electrochemical behavior of ferrite during the spinodal decomposition, which results in the absence of selective etching of ferrite. This has earlier been observed by for example Mraz et al. ${ }^{[26]}$ who reported the reduction of contrast between ferrite and austenite after the spinodal decomposition in a cast duplex stainless steel. It has been reported that ferrite and austenite had the same nobility after 5-h heat treatment of 2205 grade DSS at $475^{\circ} \mathrm{C}$, which was attributed to the presence of nano-sized $\alpha^{\prime}$ regions enriched in $\mathrm{Cr}$. ${ }^{[12]}$

Hardness is another important easily observable property that can be used to monitor $475^{\circ} \mathrm{C}$-embrittlement. However, small changes (about 5 to $10 \mathrm{HV}$ ) in hardness are not a satisfactory evidence for phase separations. Therefore, early stage phenomena are not easily studied by hardness testing as no significant changes will occur. In the present study, however, microhardness mapping showed small changes when compared to the microhardness before arc heat treatment and in surrounding regions heat treated at other temperatures. In addition, the different etching responses around the $475^{\circ} \mathrm{C}$ isotherm facilitated monitoring earlier stage embrittlement by microhardness mapping. However, the electrolytical etching approach was more effective in detecting $475^{\circ} \mathrm{C}$-embrittlement at the very early stages as it responded to smaller phase separations in ferrite than was needed to see a change in hardness.

\section{Kinetics}

One of the more interesting observations in the present study was the rapid development of phase separations in ferrite which were detectable after 3 minutes arc heat treatment. A TTT diagram presented in the industry datasheet for $2507 \mathrm{SDSS}^{[5]}$ suggests a 50 pct toughness drop after about 3-minute heat treatment at $475^{\circ} \mathrm{C}$, which is in good agreement with the etching response in this study. Hilders et al. ${ }^{[6]}$ and Gutiérrez-Vargas et al., ${ }^{[7]}$ however, reported minor changes in microhardness after 1 -h heat treatment and a toughness drop only after 72 hours at $475^{\circ} \mathrm{C}$ for the same alloy. One reason could be different levels of residual stresses in the as-received plates as this could significantly affect the kinetics of the phase separations. $^{[27,28]}$

The maximum hardness after arc heat treatment and percentage of maximum hardness increase are shown in Figure 11. The reason to use maximum hardness is to see the maximum changes that occurred in the FGMs compared to the condition prior to heat treatment.

A larger temperature range of phase separations and a larger hardness increase are to be expected for longer heat treatment times as shown in Figure 11 and Table II. However, the fact that phase separations were observed in the BM down to $405{ }^{\circ} \mathrm{C}$ after 600 minutes (10 hours) heat treatment indicates a high susceptibility to $475^{\circ} \mathrm{C}$-embrittlement at relatively low temperatures and short exposure times.

BM, RBM, and RWM had quite similar temperature ranges where phase separations were observed, but the corresponding hardness values were quite different after 10-minute arc heat treatment. Three different combinations of initial conditions can be compared as follows:

A. Different initial microstructural morphology/similar chemical composition RMB showed a higher hardness increase than BM, as shown in Figure 11, which implies that remelting accelerates the $475^{\circ} \mathrm{C}$-embrittlement. Welding introduces residual stresses which significantly accelerate phase separations. ${ }^{[27,28]}$ In addition, alloying element partitioning may affect the kinetics of phase separation. Hosseini et al. ${ }^{[29]}$ showed that autogenously remelting of 2507 SDSS decreased the partitioning of $\mathrm{Ni}$ to austenite and $\mathrm{Cr}$ and Mo to ferrite compared to the base material in as-received condition.

B. Similar initial microstructural morphology/different chemical compositions The maximum hardness increase is 3.0 pct higher for RWM than for RBM although the maximum hardness is higher for RBM than RWM. This implies that the spinodal decomposition is more rapid in the RMW. It has been suggested that the higher content of $\mathrm{Ni}$ in the RWM may promote phase separations in this temperature range. ${ }^{[24,27]}$ This is in line with the fact that 


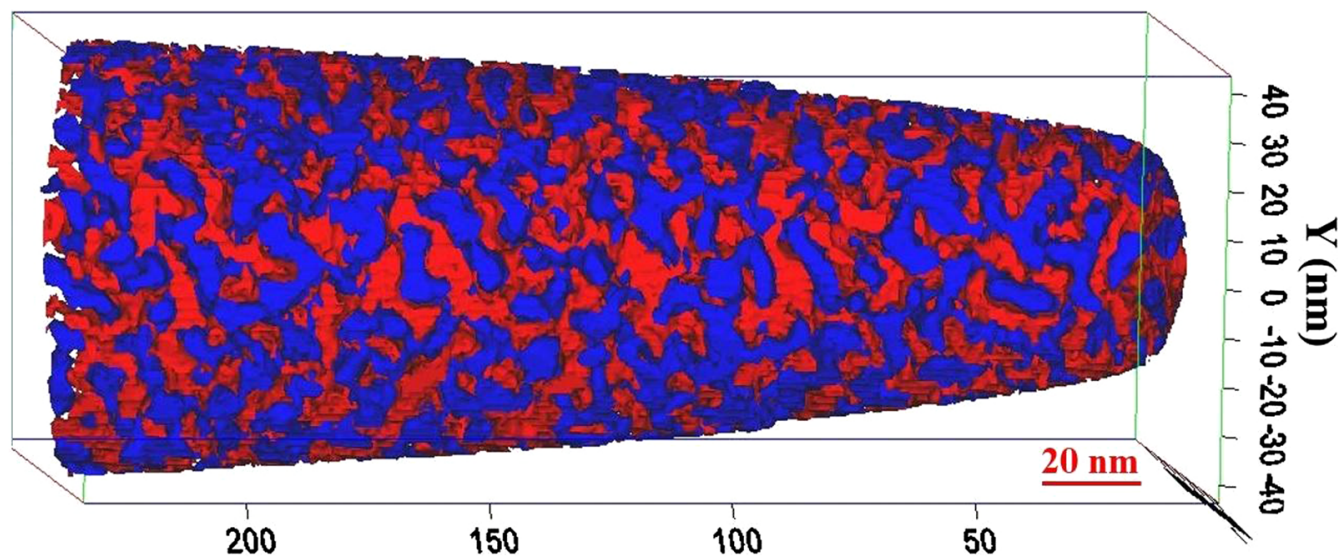

(a)

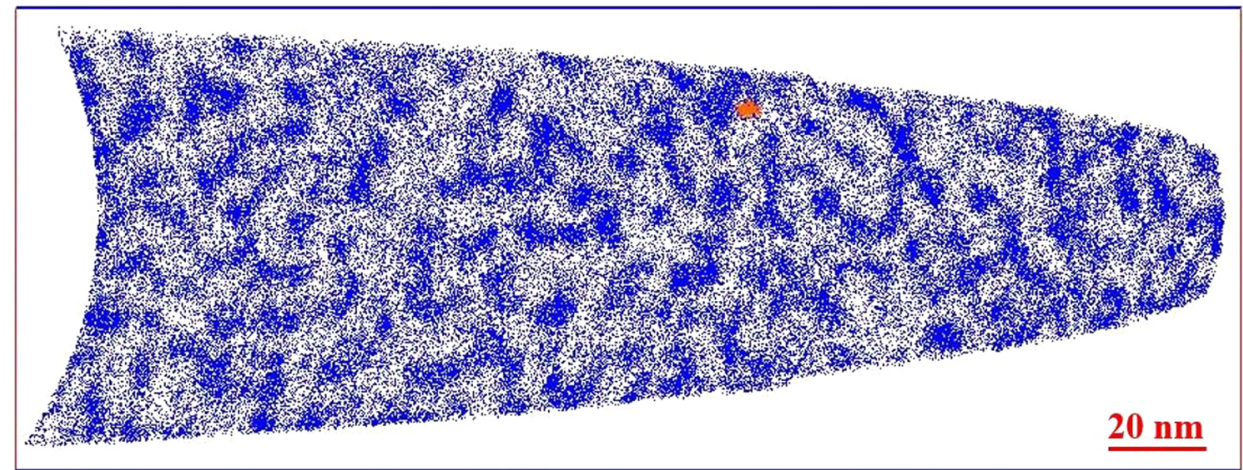

(b)

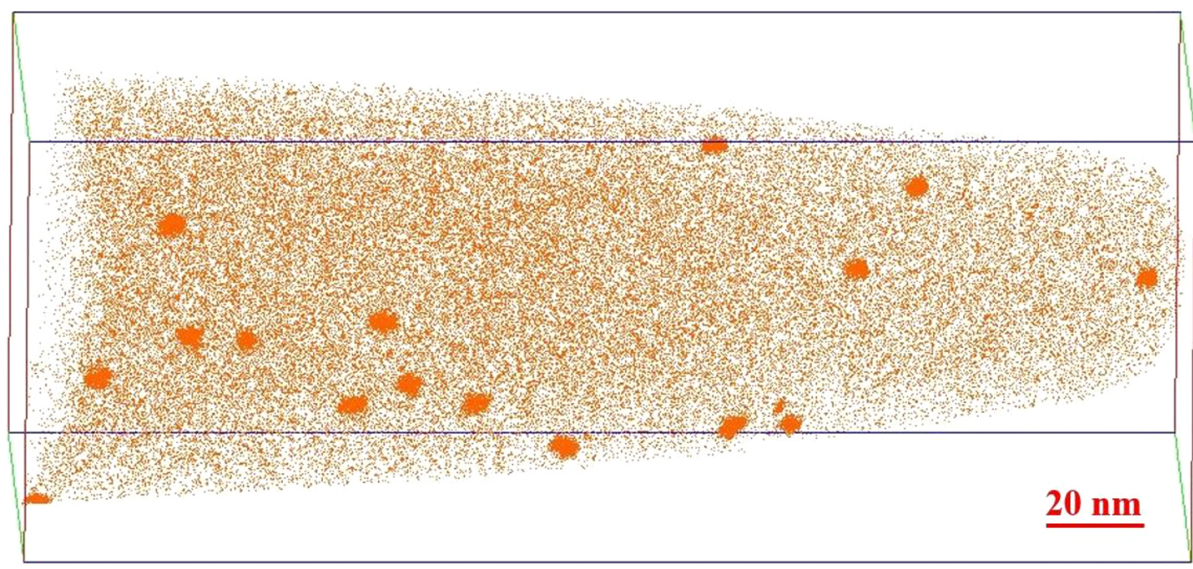

(c)

Fig. 9-Atom probe tomography images from ferrite of BM specimen furnace heat treated for 600 min at $475^{\circ} \mathrm{C}$. (a) Iso-concentration surfaces for high $\mathrm{Cr}$, shown in blue ( $>30$ at. pct), and high $\mathrm{Fe}$ regions, shown in red ( $>70$ at. pct). (b) 2D image for $\mathrm{Cr}$ (blue) and $\mathrm{Cu}$ (orange), obtained from a 2-nm-thick slice $(c) 3 \mathrm{D}$ image of $\mathrm{Cu}$ atoms clearly showing the presence of $\mathrm{Cu}$-rich precipitates (Color figure online).

thermodynamic calculations showed that the ratio of $\alpha^{\prime} / \alpha$ is higher at equilibrium for the high $\mathrm{Ni}$ welding wire composition.

C. Different initial microstructural morphology/different chemical compositions The increase in the maximum hardness of RWM is not only higher than for BM arc heat treated for 10-minute arc, but also higher than for $\mathrm{BM}$ arc heat treated for 60 minutes. This indicates that the combination of higher Ni content and weld metal microstructural morphology significantly accelerated phase separations. This phenomenon is in line with the study by Zhou et al., ${ }^{[27]}$ who reported that weld metal with higher Ni content is more prone to $475^{\circ} \mathrm{C}$-embrittlement. 


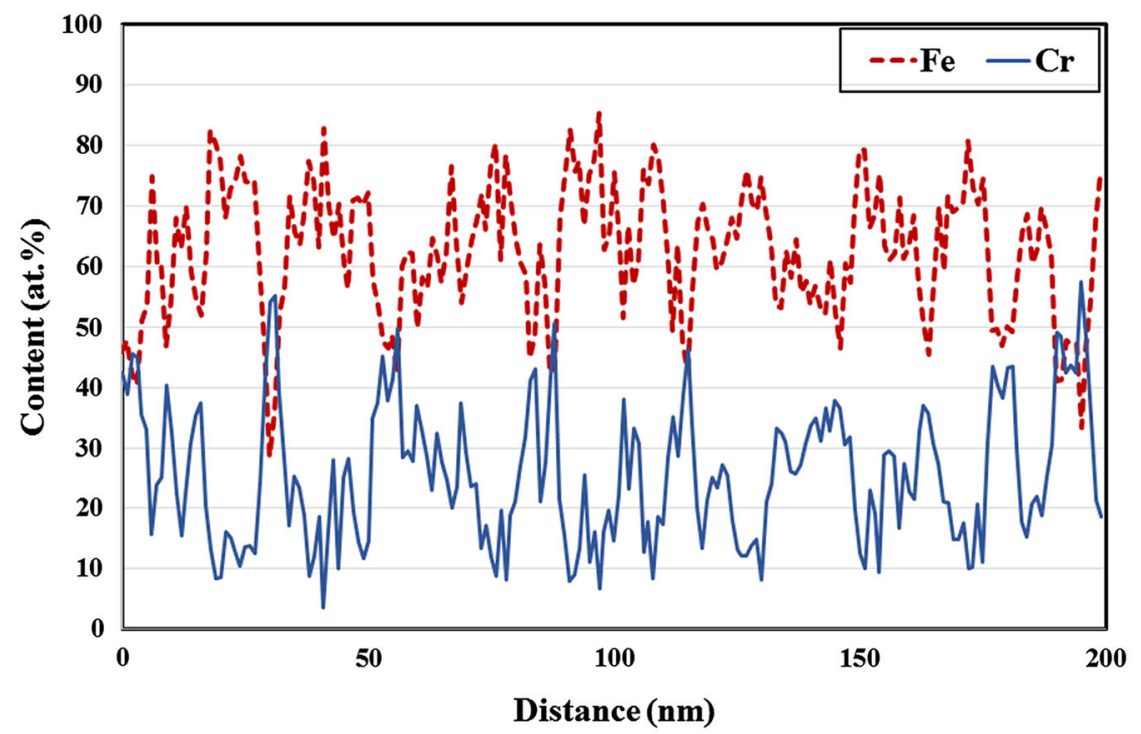

(a)

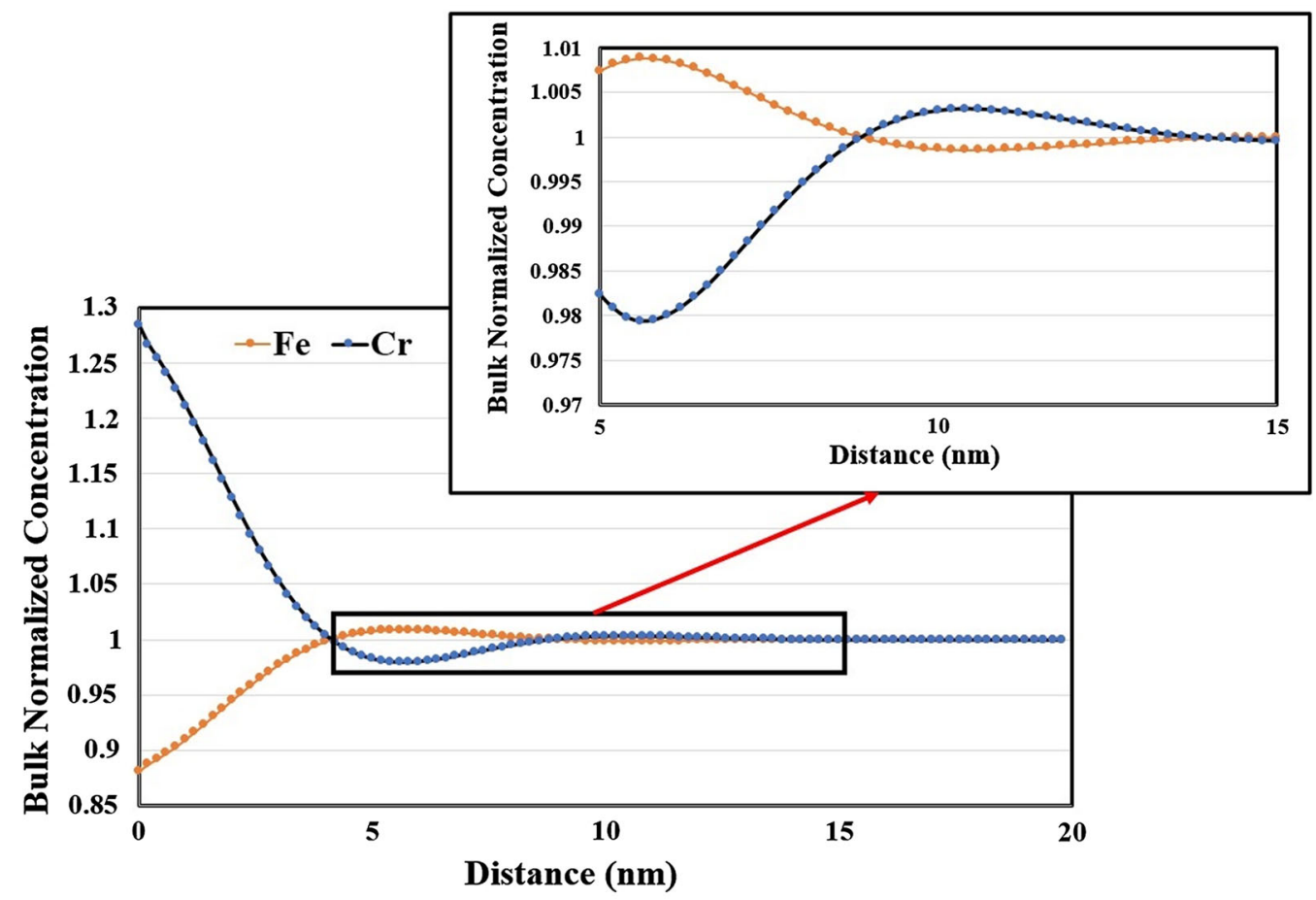

(b)

Fig. 10 - (a) Line profiles from a cylinder with a 2-nm diameter for the concentrations of $\mathrm{Fe}$ and $\mathrm{Cr}$, illustrating decomposition into Fe-rich and $\mathrm{Cr}$-rich ferrite, $(b) \mathrm{Cr}$-Cr and $\mathrm{Cr}-\mathrm{Fe}$ RDF diagram showing the normalized $\mathrm{Cr}$ and $\mathrm{Fe}$ concentration as a function of distance. The part of the diagram indicating where the $\mathrm{Cr}$ maximum, corresponding to the wavelength, appears is shown enlarged.

\section{TTT Diagram}

A time-temperature transformation diagram for $475^{\circ} \mathrm{C}$-embrittlement is presented in Figure 12. The experimental TTT curves are from the present study, the industry data sheet ${ }^{[5]}$ and by Nilsson et al. ${ }^{[2]}$ and a theoretical curve is calculated using JMatPro. As may be seen, JMatPro and Nilsson et al. ${ }^{[2]}$ suggest much longer times for $475{ }^{\circ} \mathrm{C}$-embrittlement to occur.
The TTT diagram of 2507 SDSS suggested in this study is in good agreement with that proposed in the industry datasheet but they were determined using different approaches. As presented in Table II, an etching technique was employed to find the phase separation temperature range in the present study but a 50 pct drop in toughness was considered in the industry datasheet for this alloy. It means that, in 


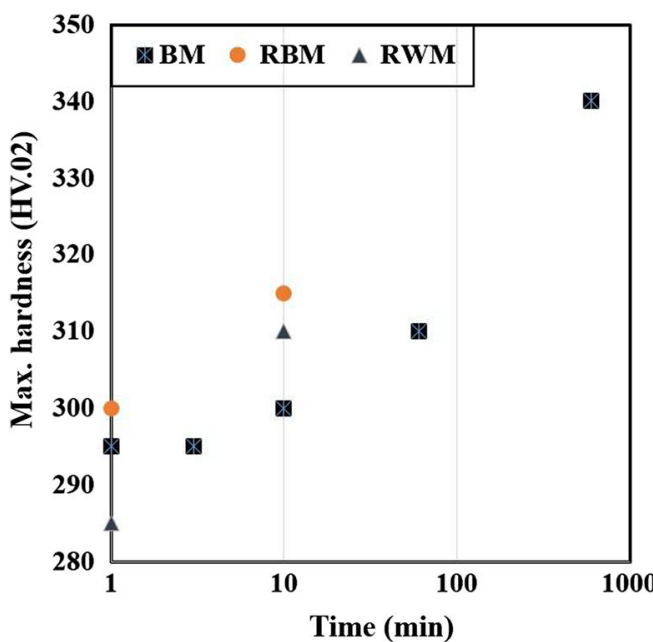

(a)

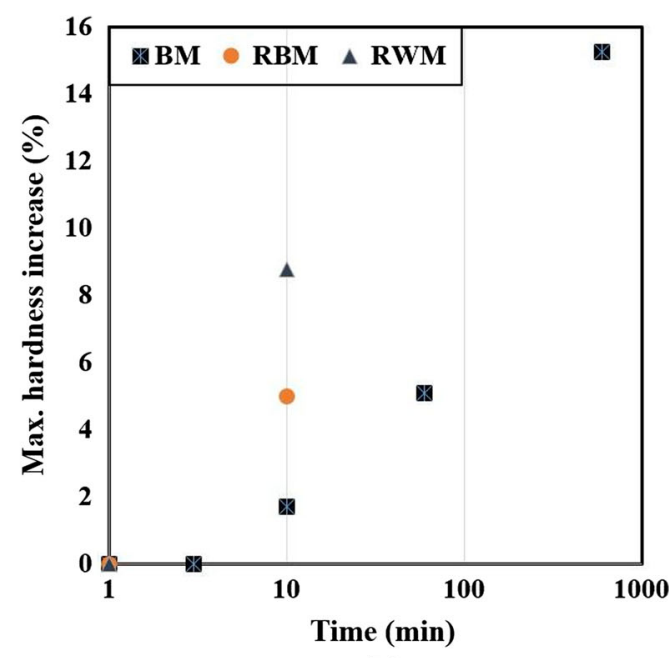

(b)

Fig. 11-(a) Maximum hardness and (b) percentage increase of maximum hardness in arc heat-treated samples. Remelted weld metal (RWM) shows the largest change in hardness after $10 \mathrm{~min}$ arc heat treatment while base metal (BM) shows the smallest.

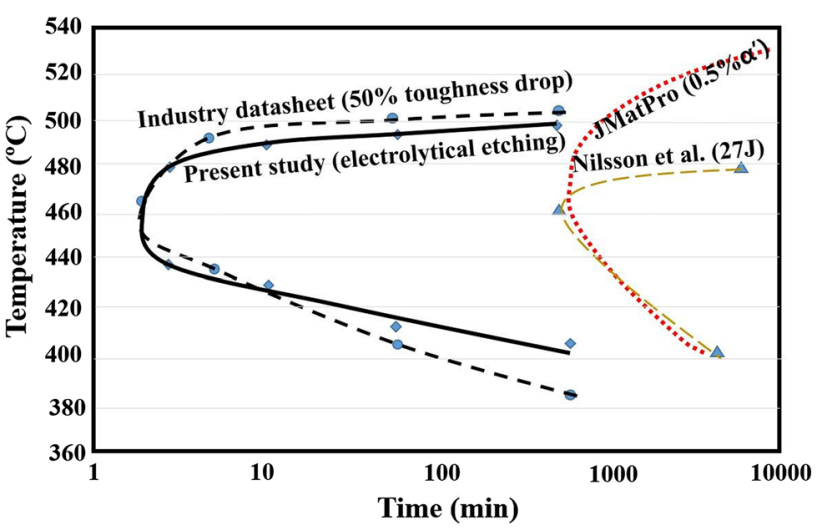

Fig. 12-Time-temperature transformation diagram for $475^{\circ} \mathrm{C}$ embrittlement of 2507 SDSS based on the present study, literature, industry datasheet, and thermodynamic calculations. A good correlation between results of this study and industry datasheet Ref. [4] for the studied base material is seen.

contrast to increase in hardness, electrolytical etching behavior shows a good agreement with a 50 pct loss of toughness approach for 2507 SDSS. This suggests that when the electrochemical behavior of ferrite is changed, the degree of spinodal decomposition is sufficient to have a detrimental influence on the toughness.

A practical implication of the observed rapid phase separations could be embrittlement during multipass welding. As an example, thermal cycle analyses performed during single pass TIG remelting of SDSS showed that regions close to the weld zone were at 400 ${ }^{\circ} \mathrm{C}$ to $500{ }^{\circ} \mathrm{C}$ about 1 minute for a 6-mm-thick plate and welding heat input of $1.1 \mathrm{~kJ} / \mathrm{mm} .{ }^{\left[{ }^{29,30]}\right.}$ During multipass welding it is therefore not unrealistic for some regions in the heat affected zone to be subjected to temperatures in the critical range for times possibly causing embrittlement. This could be the reason of unexpected loss of toughness and failures in SDSS with no detectable microstructural changes or measurable hardness increase.
However, further investigations are needed to correlate welding thermal cycles and embrittlement to verify whether this is a practical concern or not.

\section{CONCLUSIONS}

Low-temperature phase separations $\left(\mathrm{T}<500{ }^{\circ} \mathrm{C}\right)$ and embrittlement of 2507 SDSS were investigated in functionally graded base and weld metals arc heat treated between 0.5 and 600 minutes. The degree and characteristics of phase separations were studied by atom probe tomography, electrolytical etching, and microhardness mapping. The main conclusions are as follows:

1. Electrolytical etching and microhardness mapping were successfully used to monitor phase separations. The selective etching of ferrite in $10 \mathrm{pct}$ $\mathrm{NaOH}$ decreased and hardness increased as phase separation occurred.

2. First indications of phase separations in base material were found at $435{ }^{\circ} \mathrm{C}$ to $480{ }^{\circ} \mathrm{C}$ after only 3 -minute arc heat treatment. The temperature range increased to $405{ }^{\circ} \mathrm{C}$ to $500{ }^{\circ} \mathrm{C}$ after 600 minutes accompanied by a hardness increase of 14 pct. Temperature ranges were quite similar for base metal, remelted base metal and remelted weld metal arc heat treated for 10 minutes, while the hardness increase was highest in remelted weld metal and lowest in base metal.

3. Thermodynamic calculations predicted the formation of $\alpha+\alpha^{\prime}, \mathrm{Cu}$ precipitates, carbides, G-phase, Pi-nitrides, and Laves in ferrite.

4. Atom probe tomography showed $\mathrm{Cu}$ precipitates and spinodal decomposition of base metal ferrite to $\alpha+\alpha^{\prime}$, with a $\mathrm{Cr}$ amplitude of 14 at. pct and spinodal wavelength of $10.5 \mathrm{~nm}$, after 600 -minute heat treatment at $475{ }^{\circ} \mathrm{C}$.

5. A weld metal microstructure morphology and/or higher content of $\mathrm{Ni}$ accelerated phase separations. 
This was in line with thermodynamic calculations predicting higher ratio of $\alpha^{\prime} / \alpha$ for higher $\mathrm{Ni}$ contents.

6. A time-temperature transformation diagram, summarizing the kinetics of the $475{ }^{\circ} \mathrm{C}$-embrittlement, was produced for 2507 SDSS based on electrolytical etching response and literature data.

\section{ACKNOWLEDGMENTS}

The authors would like to thank Dr. Dirk Engelberg and Mr. Pierfranco Reccagni for their valuable inputs to the project, Dr. Matthew Roy and Mr. Daniel Wilson for their assistance with automatic hardness testing, Mr. Kjell Hurtig and Mr. Jonas Olsson for performing heat treatment, and Outokumpu $\mathrm{AB}$ for donating the plates. The financial support from the KK-foundation for the research school SiCoMaP (20140130) is acknowledged.

\section{OPEN ACCESS}

This article is distributed under the terms of the Creative Commons Attribution 4.0 International License (http://creativecommons.org/licenses/by/4.0/), which permits unrestricted use, distribution, and reproduction in any medium, provided you give appropriate credit to the original author(s) and the source, provide a link to the Creative Commons license, and indicate if changes were made.

\section{REFERENCES}

1. L. Karlsson: Weld. World, 2012, vol. 56, p. 6.

2. J.-O. Nilsson and G. Chai: In Duplex Stainless Steel Conference, Beaune, France, 2010.

3. C. Örnek, M. Burke, T. Hashimoto, J. Lim, and D. Engelberg: Mater. Perform. Charact., 2017, vol. 6, pp. 409-36.

4. C. Örnek, M.G. Burke, T. Hashimoto, and D.L. Engelberg: Metall. Mater. Trans. A, 2017, vol. 48A, pp. 1653-65.

5. Handbook of Stainless Steel. Outokumpu Oyj, Finland, 2013.
6. O. Hilders and N. Zambrano: J. Microsc. Ultrastruct., 2014, vol. 2, pp. 236-44.

7. G Gutiérrez-Vargas, V.H. López, H. Carreón, J. Kim and A. Ruiz: AIP Conference Proceedings, AIP Publishing. 2017, p. 110018.

8. K.L. Weng, H.R. Chen, and J.R. Yang: Mater. Sci. Eng. A, 2004, vol. 379, pp. 119-32.

9. S.S.M. Tavares, R.F. De Noronha, M.R. Da Silva, J.M. Neto, and S. Pairis: Mater. Res., 2001, vol. 4, pp. 237-40.

10. K. Chandra, R. Singhal, V. Kain, and V.S. Raja: Mater. Sci. Eng. A, 2010, vol. 527, pp. 3904-12.

11. J. Ejenstam, M. Thuvander, P. Olsson, F. Rave, and P. Szakalos: J. Nucl. Mater., 2015, vol. 457, pp. 291-97.

12. C. Örnek, J. Walton, T. Hashimoto, T.L. Ladwein, S.B. Lyon, and D.L. Engelberg: J. Electrochem. Soc., 2017, vol. 164, pp. C207-17.

13. X. Xu, J. Odqvist, M.H. Colliander, M. Thuvander, A. Steuwer, J.E. Westraadt, S. King, and P. Hedstrom: Metall Mater Trans A, 2016, vol. 47A, pp. 5942-52.

14. J.-O. Nilsson and P. Liu: Mater. Sci. Technol., 1991, vol. 7, pp. 853-62.

15. J. Zhou, J. Odqvist, M. Thuvander, S. Hertzman, and P. Hedström: Acta Materialia, 2012, vol. 60, pp. 5818-27.

16. T.F. Kelly and M.K. Miller: Rev. Sci. Instrum., 2007, vol. 78, p. 031101 .

17. L.D. Bobbio, R.A. Otis, J.P. Borgonia, R.P. Dillon, A.A. Shapiro, Z. Liu, and A.M. Beese: Acta Materialia, 2017, vol. 127, pp. 133-42.

18. V.A. Hosseini, L. Karlsson, K. Hurtig, I. Choquet, D. Engelberg, M.J. Roy, and C. Kumara: Mater. Des., 2017, vol. 121, pp. 11-23.

19. S. Hertzman, R. Pettersson, R. Blom, E. Kivineva, and J. Eriksson: ISIJ Int., 1996, vol. 36, pp. 968-76.

20. J. Zhou, J. Odqvist, M. Thuvander, and P. Hedström: Microsc. Microanal., 2013, vol. 19, pp. 665-75.

21. C. Kumara: Modelling of the Temperature Field in TIG Arc Heat Treated Super Duplex Stainless Steel Samples, Master thesis, University West, Sweden, 2016.

22. N. Pettersson, S. Wessman, M. Thuvander, P. Hedström, J. Odqvist, R. Pettersson, and S. Hertzman: Mater. Sci. Eng. A, 2015, vol. 647, pp. 241-48.

23. J. Zhou, J. Odqvist, L. Höglund, M. Thuvander, T. Barkar, and P. Hedström: Scr. Mater., 2014, vol. 75, pp. 62-65.

24. B. Zhang, F. Xue, S.L. Li, X.T. Wang, N.N. Liang, Y.H. Zhao, and G. Sha: Acta Mater., 2017, vol. 140, pp. 388-97.

25. A. Weidner, R. Kolmorgen, I. Kubena, D. Kulawinski, T. Kruml, and H. Biermann: Metall. Mater. Trans. A, 2016, vol. 47A, pp. $2112-24$

26. L. Mraz, F. Matsuda, Y. Kikuchi, N. Sakamoto, and S. Kawaguchi: Trans. JWRI, 1994, vol. 23 (2), p. 10.

27. J.K. Sahu, U. Krupp, R.N. Ghosh, and H.J. Christ: Mater. Sci. Eng. A, 2009, vol. 508, pp. 1-14.

28. F. Danoix, J. Lacaze, A. Gibert, D. Mangelinck, K. Hoummada, and E. Andrieu: Ultramicroscopy, 2013, vol. 132, pp. 193-98.

29. V.A. Hosseini, S. Hurtig, and L. Karlsson: Mater. Des., 2016, vol. 98 , pp. 88-97.

30. V.A. Hosseini, M.V. Bermejo, J. Gårdstam, K. Hurtig, and L. Karlsson: Weld. World, 2016, vol. 60, pp. 233-45. 